\title{
Proceeding
}

Supplementary Issue: Spring Conferences of Sports Science. Costa Blanca Sports Science Week, 26-28 April 2018. Calpe. Alicante, Spain

\section{An educational behaviour lifestyle-based program to prevent risk factors of type 2 diabetes among older adults}

\author{
JESUS DEL POZO-CRUZ1 \\ JUAN ANTONIO CORRAL PERNÍA ${ }^{1}$, FÁTIMA CHACÓN BORREGO¹, \\ ROSA M. ALFONSO-ROSA ${ }^{2}$ \\ ${ }^{1}$ Department of Physical Education and Sports. University of Seville, Seville, Spain \\ ${ }^{2}$ Motricity and Human Performance Area, University of Seville, Seville, Spain
}

\begin{abstract}
Objective. To test the effectiveness of a 12-wk educational-based program on glycaemic control, body composition, functional capacity and health related quality of life among type 2 diabetes mellitus older patients. Methods. Twenty-three non-insulin dependent T2DM patients were include in this cuasiexperimental study. A pre-post study was performance. Outcomes including fasting blood glucose, body composition, functional capacity and health related quality of life were assessed at baseline and after 12-wk intervention. Results. After intervention, there was a reduction of fasting blood glucose, with an effect size of 0.50 . Similarly, after intervention great values were found in BMI $(p<0,05)$ and functional capacity (T6MWT and handgrip test). Health related quality of life was improved (physical functioning dimension with a statically significance $<0.05$ ). Conclusion. A 12-wk educational-based program could improve and management the disease, improving glycaemic profile, functional capacity, body composition and psychosocial status among T2DM patients. Key words: T2DM, PREVENTION, LIFESTYLE, HEALTH-RELATED QUALITY OF LIFE (HRQOL); FUNCTIONAL CAPACITY.
\end{abstract}

\section{Cite this article as:}

del Pozo-Cruz, J., Corral Pernía, J.A., Chacón Borrego, F., \& Alfonso-Rosa, R.M. (2018). An educational behaviour lifestyle-based program to prevent risk factors of type 2 diabetes among older adults. Journal of Human Sport and Exercise, 13(2proc), S320-S328. doi:https://doi.org/10.14198/ihse.2018.13.Proc2.16

Corresponding author. Department of Physical Education and Sports. University of Seville, Seville, Spain.

E-mail: jpozo2@us.es

Supplementary Issue: Spring Conferences of Sports Science. Costa Blanca Sports Science Week, 26-28 April 2018. Calpe. Alicante, Spain.

JOURNAL OF HUMAN SPORT \& EXERCISE ISSN 1988-5202

(c) Faculty of Education. University of Alicante

doi: 10.14198/jhse.2018.13.Proc2.16

S320 | 2018| Proc2| VOLUME 13

C 2018 University of Alicante 


\section{INTRODUCTION}

Aging is a multifactorial process resulting in damage of molecules, cells, and tissues, leading to a reduce the efficacy of physiological functions with different pathological consequences (del Pozo-Cruz, et al., 2014). Type 2 diabetes mellitus (T2DM) is a metabolic disorder characterized by hyperglycaemia and insufficient secretion or action of endogenous insulin (ADA, 2014; Leal et al., 2017). Moreover, patients with type 2 diabetes are characterized by high adiposity and reduced fitness, predictors of the health related quality of life (Alfonso-Rosa-et al., 2012; Hernández et al., 2016). Like-wise, T2DM is an independent risk factor for vascular diseases and also is frequenly associate with other cardiovascular diseases (Koelmeyer et al., 2016; Alfonso-Rosa et al., 2013).

Along with nutrition, exercise has long been recognized as a part of the non pharmacological treatmen and management of type 2 diabetes. Although there no definitive conclusions, results from diferents metaanalysisis, suggest that different types of exercise (i.e. arecobic exercise, resistance trining or combined trainning) reduce fasting blood glucose when compared with standard care and treatment. In line with this, there is a substantial evidence from multiple randomised controlled trials indicating that T2DM can be improved or at least controlled by lifestyle changes (Troughton et al., 2016). Differents lifestyle modification programs have showed an acceptable effectivity ratio. Previous studies have showed to be effectives in the management of risk factors associated to the T2DM (Wu et al., 2017). However, many of this programs are based on supervised exercise and physical activity, and also a few programs included a plus of conseuling and educational tasks in their programs (Alfonso-Rosa, 2013). To the best of our knowledge, none of this studies have assessed the effects of an educational behavioral lifestyle program on T2DM. Therefore, the main aim of this study was to assess the effectivness of apply a 12- week educational program to reduce the risks factors associated with a T2DM in older people.

\section{MATERIALS AND METHODS}

\section{Study design and participants}

A cuasi-experimental study (pre-post intervention) was conducted. The study was approved by the research ethics committee of the university and conducted according to the declaration of the Helsinki, as revised in Edinburgh, 2008. After public information, all participants signed an informed consent form prior to participation in the study. All participants, were recruited from the same Diabetes Association. Criteria inclusion included: age as least 60 years old and were community-dwelling people from the zone where the study was performance. Potential participant was excluded if they had a pacemaker, knee injury, hip or knee prosthesis, hernia, cardiac or other systemic disease, not well balance with medical treatment, diabetic neuropathy or severe vertigo. Out of 55 eligible participants, 34 showed interest and finally 23 fulfilled the inclusion/exclusion criteria and were included in the study.

\section{Procedures and Experimental protocol}

Participants had access to the usual care (consisting on outpatient visit for the control of the diabetes-related parameters) and were asked do not change their nutritional status unless was advice by the protocol of the study. Intervention consisted in a 12-week behavioural and educational program based on physical activity advices.

Once a week during 12-weeks (120 minutes per session), participants were asked to meet in the association. The protocol involved reviewing previous research on barriers to physical activity and identify the key 
emotions, beliefs, control factors, skills, etc. Fasting blood glucose were assessed in each session and participants were educated and asked to increase walking-based physical activity.

\section{Outcomes measures}

Socio-demographic variables (i.e. age, gender) as well as clinical predictor variables were recorded. Weight, height, and waist to hip circumference were measured to calculate body-mass index (BMl; $\mathrm{Kg} / \mathrm{m}^{2}$ ) and waist to hip ratio. Outcome measured were assessed at baseline and after the 12-wk study period.

\section{Fasting blood glucose and functional capacity}

Fasting blood glucose $(\mathrm{mg} / \mathrm{dl})$ was assessed each time for 12 weeks. To assed functional capacity, a test battery consisting of three assessments was used. Motor agility and mobility were assessed by the Time Up and Go test. The participant had to stand up from a chair, walk $3 \mathrm{~m}$ to and around a cone, and return to the chair in the shortest time possible. The best time of two trials was recorded. To evaluate the cardiovascular status, the Six Minute Walking Test (6MWT) was conducted. Participants were instructed to walk as far as possible within run. The maximum distance $(\mathrm{m})$ walked was recorded as the score of the test.

Muscle performance was assessed using the 30-s Chair Sit to stand test. Participants were instructed to performance the test where initial position and final position was the same (sit). The number of times within $30 \mathrm{~s}$ that the participant could raise to a full stand from a seated position as fast as possible. The peak force was recorded using a Kistler force platform, type 9281A (Kistler Instruments AG, Winterthur, Switzerland). The peak during the performance 30 CSTS test was then recorded.

Health-related quality of life

The SF36 health survey was used to assess the health-related quality of life. The SF36 include 36 dimensions (physical functioning, social functioning, rol limitations-physical and social problems-, pain, mental health, vitality and general health perception).

\section{Statistical analysis}

Analysis was performed using SPSS version 17.0 (SPSS Inc, Chicago, IL, USA). The significance level was set at $p<0.05$ for all analysis. The distribution of the data was determined by the Kolmorov-Smirnov test. After that, paired t-test was performance to test the different between baseline and postintervention values. In addition, Effect size was calculated as the difference between means divided by the pooled standard deviation. Cohen's coefficient was used to assed the possible change in the variable.

\section{RESULTS}

23 participants aged plus 60 were included in the study. The baselines socio-demographic, clinical and body compositions variables were compared (table 1). Statically differences were found between pre and post tests on BMl and weight variables. Non-statically differences were found for the rest of variables compared. Effect size was over 0.3 in all cases.

\section{Fasting blood glucose}

No statically differences between baseline values and post intervention values were observed for fasting blood glucose. Although no statically differences were found, participants in the post intervention moment exhibited greater (lower) values of fasting blood glucose with an effect-size of 0.50 . 
Table 1. Sociodemographic and anthropometrics characteristics of the participants in the study $(n=23)$.

\begin{tabular}{|c|c|c|c|c|}
\hline Variable & Pre-test & Post-test & $p$ & Effect-size \\
\hline Sex (\%female) & 47.83 & 47.83 & - & - \\
\hline Age (years) & 63.96 & 63.96 & - & - \\
\hline Height $(\mathrm{cm})$ & 163.65 (11.44) & $163.33(11.26)$ & - & - \\
\hline Weight (Kg) & 77.14 (21.94) & 75.12 (19.78) & $0.08^{*}$ & 0.38 \\
\hline $\mathrm{BMI}\left(\mathrm{kg} / \mathrm{m}^{2}\right)$ & $28.63(6.44)$ & $27.96(6.24)$ & $0.035^{\star}$ & 0.45 \\
\hline$\%$ Body fat & $36.43(7.27)$ & 35.85 (7.95) & $0,140^{*}$ & 0.33 \\
\hline WHR & 0.98 & 0.95 & $0.089^{*}$ & 0.38 \\
\hline
\end{tabular}

Values are mean (SD) unless otherwise indicated; BMI, body mass index; WHR, waist to hip ratio; $p, p$ value from pairedt test.

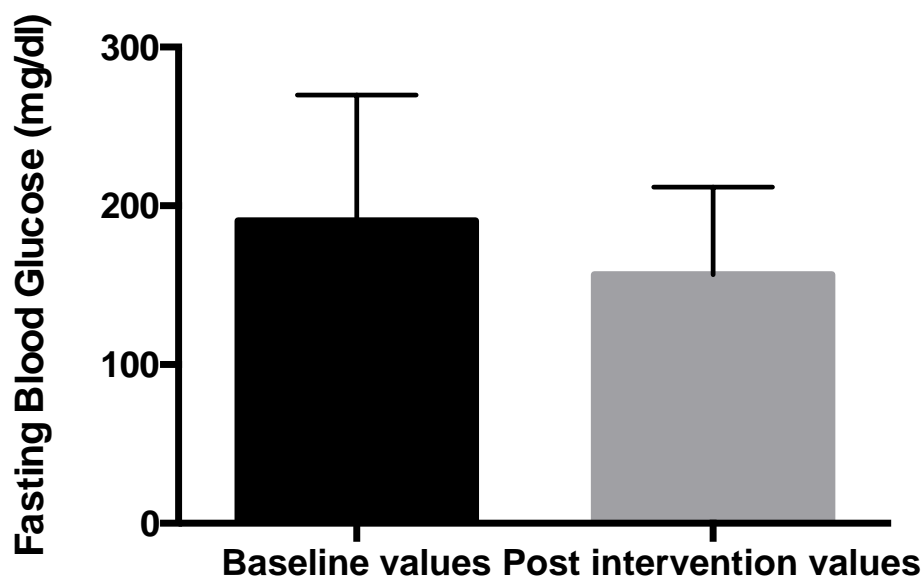

Figure 1. Effects of 12-wk educational program on fasting blood glucose. The graph shows fasting blood glucose levels (mg/dl) with baselines values of 190,63(79,31) and 166,00 $(54,40)$ for post intervention values in older adults with T2DM $(n=23)$.

\section{Functional Capacity}

Table 2 shows the effects of 12 weeks of behavioural education program on the fitness levels of the participants in the study. Statically different were founds the baseline and post intervention values on the 
handgrip (right and left side) variables $(p<0,05)$ and in the 30-s CSTS peak power assessed with a force platform. No statically different were found in the rest of variables. However, we did detect a moderate effect size for the six-minute walking test (0.19).

Table 2. Effects of 12-wk educational program on functional capacity in older adults with T2DM $(n=23)$.

\begin{tabular}{|c|c|c|c|c|}
\hline Variable & Pre-test & Post-test & $p$ & Effect-size \\
\hline HANDGRIPleft (kgsm-2) & $20.18(9.09)$ & $22.47(8.42)$ & $0.011^{*}$ & 0.12 \\
\hline HANDGRIPright (kgsm-2) & $22.54(10.42)$ & $24.65(9.02)$ & $0.021^{*}$ & 0.10 \\
\hline 30-s CSTS (number of times) & $9.87(1.94)$ & $9.35(1.41)$ & 0.263 & 0.14 \\
\hline 30-s $\operatorname{CSTS}^{*}(\mathrm{~N})$ & $816.0(235.66)$ & $926.64(253.33)$ & $0.000^{*}$ & 0.22 \\
\hline TUG (s) & $7.49(2.07)$ & $6.93(1.57)$ & 0.106 & 0.15 \\
\hline 6MWT (m) & $374.99(81.04)$ & $412.00(104.43)$ & 0.104 & 0.19 \\
\hline
\end{tabular}

Values are mean (SD) unless otherwise indicated; 30-s CTS: 30 seconds Chair Sit to Stand test; 30-s CSTS*: 30-s CSTS peak power y el encoder lineal. TUG: Timed Up and Go Test; 6MWT: Six Minutes Walking Test.

\section{Health related quality of life}

Scores from different dimensions of the SF36 questionnaire, show statically difference between baseline and post intervention group on the physical functioning dimension $(p<0.05)$. Although no statically differences were observed in the rest of dimensions, in general upper scores were found for rol limitations and mental health dimensions while lower scores were exhibited for pain and vitality dimensions. Effect size show and over score 0.19 for the rol limitation dimension (table 3). 
Table 3. Effects of 12-wk educational program on health-related quality of life in older adults with T2DM $(n=23)$.

\begin{tabular}{lcccc}
\hline Dimensions SF36 & Pre-test & Post-test & $p$ & Effect-size \\
\hline Physical functioning & $68.69(22.52)$ & $74.08(24.09)$ & $\mathbf{0 . 0 2 8 ^ { * * }}$ & 0.11 \\
Social functioning & $82.07(25.23)$ & $80.87(24.65)$ & 0.500 & 0.02 \\
& & & & \\
Rol limitations (physical problems) & $61.96(44.51)$ & $69.51(38.39)$ & 0.380 & 0.09 \\
& & & & \\
Rol limitations (social problems) & & & & \\
& $68.12(46.58)$ & $84.27(34.26)$ & 0.475 & 0.19 \\
Pain & & & & \\
& $60.35(28.21)$ & $56.19(26.95)$ & 0.314 & 0.07 \\
Mental health & & & & \\
Vitality & $65.74(25.43)$ & $67.31(25.75)$ & 0.102 & 0.03 \\
General health perception & $58.69(28.05)$ & $57.86(24.40)$ & 0.857 & 0.04 \\
\hline
\end{tabular}

Values are mean (SD) unless otherwise indicated SF36 (Short Form 36 Health Survey).

\section{DISCUSSION}

A cuasi-experimental design was used to evaluate the effectiveness of a 12-wk educational behaviour lifestyle-based intervention added to standard care among T2DM older adults patients on fasting blood glucose, functional capacity and health related quality of life. The main findings were that patients of the study trends reduce the fasting blood glucose after the application of the program. Moreover, functional capacity was also improve following the intervention in these participants. Thus, the results of our study are promising and of value to health care practitioners who treat T2DM patients.

Using exercise and physical activity as a health care, previous literature on T2DM population and sedentary people have reported improvements in different outcomes (Yu et al., 2017). Other authors tested how WBV exercise in a high frequencies reported improvements in fasting blood glucose as well as our results (AlfonsoRosa et al., 2014). Therefore we aimed the educational conseuling physical activity-based as therapy.

Although $\mathrm{HbA} 1 \mathrm{c}$ is considered the optimal way to assess long-term glycemic control, with $\mathrm{HbA} 1 \mathrm{c}$ values of $<7.0 \%$ acceptes as representing good glucose control (del Pozo-Cruz et al., 2014), fasting blood glucose may be considered a good marker to control and management the T2DM (Cabrera et al., 2004). Our results showed an decrease of fasting blood glucose between baseline values and postintervention values. Along with this results, previous literatur have show how promotion health programs could reduce the same parameter (Balk et al., 2015). 
Cardiovascular disease is related with Weight and BMl in older adults an is the leading cause of death among individuals with T2DM (Dickerson et al., 2011), and therefore the management of this risk factors for the disease is a priority among researchers and health care practiotioners. In our study, stastistically significant were found, where lower values were showed after intervention. Although others authors have reported similar results after helath promotion program, no previous studies have applied only educational programs according with us. However, further study is needed to make direct comparisions and draw definitive conclusions on this fact.

As expected from the previous literature and reviews of exercise training, our patients experienced an improvement in functional lower limb and upper strength. Moreover, T2DM patients included in our study reported and improvement on aerobic capacity assessed by T6MWT. It has been suggested that T2DM may have control problems associated with peripheral sensoty impairment and a dcrease in their functional capacity (Sañudo Corrales et al., 2014). There is evidence that exercise is effective for lowering the risk and can improve the balance, gait and in general functional capacity, include aerobic fitness (Alvarez- Barbosa et att., 2014).

The results presented from the current study need to be considered in the context of its limitations. The fact that we did not use a population-based approach could limit the generalization of the results. Moreover, the use of a cuasi-experimental design to performance this study could limit the understanding of the results. Despite the effectiveness shown in the current study, we have not determined the dose-response relationship for educational program and therefore further studies are needed to provide an optimal intervention for T2DM patients. Finally analysis of cost-effectiveness is warranted to enhance the decision-making process of policy makers on the implemntation of this tye of intervention.

\section{CONCLUSIONS}

The application of a 12-wk educational behaviour lifestyle program to prevent risk factors in T2DM setting is feasible and effective to reduce risk factors associate with type 2 diabetes in older community-dwelling people, improve performance in activities of daily living and increase health related quality of life in older people with T2DM. Although results are clear, more research is necessary with an RCT design in order to confirm these results. Moreover, our results could help to operate as a model for T2DM management in this population.

\section{REFERENCES}

ADA. (2014). Standards of Medical Care in Diabetes-2014. Diabetes Care 2014. Diabetes Care, 37(3), 887-887. https://doi.org/10.2337/dc14-er03

Alfonso-Rosa, R. M.; del Pozo-Cruz, B.; del Pozo-Cruz, J.; del Pozo-Cruz, J.T. \& Sañudo, B. (2013). The relationship between nutritional status, functional capacity, and health-related quality of life in older adults with type 2 diabetes: A pilot explanatory study. The journal of nutrition, health \& aging, 17(4), 315-321. https://doi.org/10.1007/s12603-013-0028-5

Alfonso-Rosa, R. M., del Pozo-Cruz, J. T., Caraballo, M., del Pozo-Cruz, J., \& del Pozo-Cruz, B. (2012). Asociación entre la condición física relacionada con la salud y la calidad de vida en pacientes diabéticos tipo 2 tratados en atención primaria: un estudio exploratorio en la provincia de Sevilla. Revista Andaluza de Medicina del Deporte, 5(3), 91-98. https://doi.org/10.1016/S18887546(12)70014-X

Álvarez, F, del Pozo-Cruz, Jesús, del Pozo-Cruz, Borja, Alfonso-Rosa, Rosa M., Rogers, Michael E., \& Zhang, Yanxin. (2014). Effects of supervised whole body vibration exercise on fall risk factors, 
functional dependence and health-related quality of life in nursing home residents aged $80+$. Maturitas, 79(4), 456-463. doi: https://doi.org/10.1016/..maturitas.2014.09.010

American Collegue Association of Sports Medicine. American Diabates. (2010). Exercise and Type 2 Diabetes: American College of Sports Medicine and the American Diabetes Association: Joint Position Statement. Medicine \& Science in Sports \& Exercise, 42(12), 2282-2303. https://doi.org/10.1249/MSS.0b013e3181eeb61c

Bacchi, E., Negri, C., Trombetta, M., Zanolin, M. E., Lanza, M., Bonora, E., \& Moghetti, P. (2012). Differences in the acute effects of aerobic and resistance exercise in subjects with type 2 diabetes: results from the RAED2 Randomized Trial. PLoS One, 7(12), e49937. https://doi.org/10.1371/journal.pone.0049937

Balk, E. M., Earley, A., Raman, G., Avendano, E. A., Pittas, A. G., \& Remington, P. L. (2015). Combined Diet and Physical Activity Promotion Programs to Prevent Type 2 Diabetes Among Persons at Increased Risk: A Systematic Review for the Community Preventive Services Task Force. Ann Intern Med, 163(6), 437-451. https://doi.org/10.7326/M15-0452

Cabrera, C.E, González, G, Vega, M.G, \& Arias, E.D. (2004). Impacto de la educación participativa en el índice de masa corporal y glicemia en individuos obesos con diabetes tipo 2. Cadernos de Saúde Pública, 20, 275-281. https://doi.org/10.1590/S0102-311X2004000100045

Cántaro, K., Jara, J.A., Taboada, M., \& Mayta-Tristán, P. (2016). Asociación entre las fuentes de información y el nivel de conocimientos sobre diabetes en pacientes diabéticos tipo 2. Endocrinología y Nutrición, 63(5), 202-211. https://doi.org/10.1016/i.endonu.2016.01.005

del Pozo-Cruz, B., Alfonso-Rosa, R. M., del Pozo-Cruz, J., Sanudo, B., \& Rogers, M. E. (2014). Effects of a 12-wk whole-body vibration based intervention to improve type 2 diabetes. Maturitas, 77(1), 5258. https://doi.org/10.1016/i.maturitas.2013.09.005

Dickerson, F., Wohlheiter, K., Medoff, D., Fang, L., Kreyenbuhl, J., Goldberg, R., . . Dixon, L. (2011). Predictors of quality of life in type 2 diabetes patients with schizophrenia, major mood disorder, and without mental illness. Qual Life Res, 20(9), 1419-1425. https://doi.org/10.1007/s11136-011-9888-5

Gusi, N., Prieto, J., Olivares, P. R., Delgado, S., Quesada, F., \& Cebrian, C. (2012). Normative fitness performance scores of community-dwelling older adults in Spain. J Aging Phys Act, 20(1), 106-126. https://doi.org/10.1123/iapa.20.1.106

Hernández, M., Batlle, M. A., Martínez de Morentin, B., San-Cristóbal, R., Pérez-Díez, S., NavasCarretero, S., \& Martínez, J. A. (2016). Cambios alimentarios y de estilo de vida como estrategia en la prevención del síndrome metabólico y la diabetes mellitus tipo 2: hitos y perspectivas. Anales del Sistema Sanitario de Navarra, 39(2), 269-289.

Jones, Jessie, \& Rikli, Roberta. (2002). Measuring functional fitness of older adults (Vol. 1).

Koelmeyer, R.L., Dharmage, S.C. , \& English, D.R. . (2016). Diabetes in young adult men: social and health-related correlates BMC PUBLIC HEALTH, 16(3). https://doi.org/10.1186/s12889-016-3704-7

Leal, J., Ahrabian, D., Davies, M. J., Gray, L. J., Khunti, K., Yates, T., \& Gray, A. M. (2017). Costeffectiveness of a pragmatic structured education intervention for the prevention of type 2 diabetes: economic evaluation of data from the Let's Prevent Diabetes cluster-randomised controlled trial. 7, 1. https://doi.org/10.1136/bmjopen-2016-013592

Li, Y.; Geiss, L.S.; Burrows, N.R.; Rolka, D.B. \& Albright, A. (2013). Awareness of Prediabetes- United States, 2005-2010. Morbidity and Mortality Weekly Report, 62(11), 209-212.

Norton, K, \& Olds, T. (1995). Antropometrica . Libro de referencia sobre mediciones corporales humanas para la Educación en Deportes y Salud.Argentina: University of New South Wales Press, Sidney 2052 Australia. 
Olivares, P. R., Gusi, N., Prieto, J., \& Hernandez-Mocholi, M. A. (2011). Fitness and health-related quality of life dimensions in community-dwelling middle aged and older adults. Health Qual Life Outcomes, 9, 117. https://doi.org/10.1186/1477-7525-9-117

O.K. Bhattacharyya, B.R. Shah, G.L. BoothManagement of cardiovascular disease in patients with diabetes: the 2008 Canadian Diabetes Association guidelines.

Rodríguez, M. (2017). Nutrición y ejercicio en las personas con diabetes. Revista de la ALAD, 7, 40-49.

Rosa, Alfonso, \& Rosa, Ma . (2015). Efectividad de un programa de entrenamiento basado en vibraciones mecánicas de cuerpo completo en pacientes con diabetes mellitus tipo 2 aplicado en entorno de atención primaria.

Sallis, J. F., Cervero, R. B., Ascher, W., Henderson, K. A., Kraft, M. K., \& Kerr, J. (2006). An ecological approach to creating active living communities. Annu Rev Public Health, 27, 297-322. https://doi.org/10.1146/annurev.publhealth.27.021405.102100

Sañudo Corrales, Francisco de Borja, Rosa, Alfonso, Rosa, $M^{a}$, Pozo Cruz, Jesús del, Pozo Cruz, José Teodoro del, \& Cruz, Pozo. (2013). Influência do nível de atividade física sobre a aptidão física e qualidade de vida relacionada à saúde em idosos portadores ou não de diabetes mellitus tipo 2 . Revista Brasileira de Medicina do Esporte, 19(6), 410-314. https://doi.org/10.1590/S1517$\underline{86922013000600006}$

Troughton, J., Chatterjee, S., Hill, S. E., Daly, H., Stacey, L. M., Stone, M. A., . . Davies, M. J. (2016). Development of a lifestyle intervention using the MRC framework for diabetes prevention in people with impaired glucose regulation. Journal of Public Health, 38(3), 493-501. doi: 10.1093/pubmed/fdy110

Wu, J., Ward, E., Threatt, T., \& Lu, Z. K. (2017). Progression to Type 2 Diabetes and Its Effect on Health Care Costs in Low-Income and Insured Patients with Prediabetes: A Retrospective Study Using Medicaid Claims Data. Journal of Managed Care \& Specialty Pharmacy, 23(3), 309-316. https://doi.org/10.18553/imcp.2017.23.3.309

Yu, Sun, Wen, You, Almeida, Fabio, Estabrooks, Paul, \& Davy, Brenda. (2017). The Effectiveness and Cost of Lifestyle Interventions Including Nutrition Education for Diabetes Prevention: A Systematic Review and Meta-Analysis.117(3), 404-404-421.

\section{(9) $(\mathbb{\Theta \Theta}$}

This title is licensed under a Creative Commons Attribution-NonCommercial-NoDerivs 4.0 Unported License. 